\title{
Towards cleaner technologies minimising the environmental impact
}

\author{
Jiří Klemeš $\cdot$ Igor Bulatov
}

Published online: 19 March 2008

(C) Springer-Verlag 2008

\begin{abstract}
This editorial introduces and provides an overview of a special issue dedicated to the ninth conference on Process integration, modelling and optimisation for energy saving and pollution reduction-PRES 2006. It contains ten selected papers covering various fields of Clean Technologies and Environmental Policy, namely, catalytic and thermal cracking with natural zeolite catalyst, recovery and reutilisation of copper from sludge, aerosols monitoring by satellite observations, utilisation of high throughput technologies, CFD modelling solid biomass combustion, fluorides removal and recovery for resources saving, siloxane removal from biogas by bio filtration, software tools for water reuse evaluation, pollutants emission abatement and integrated pollution prevention and control in the surface treatment industries.
\end{abstract}

\section{Introduction}

Issues of global warming and greenhouse gas emissions together with other pollution and effluents are becoming one of the major technological and also important societal

\footnotetext{
J. Klemeš ( $₫)$

EC Marie Curie Chair (EXC) INEMAGLOW, FIT, University of Pannonia, Egyetem u. 10, 8200 Veszprem, Hungary

e-mail: klemes@cpi.uni-pannon.hu

I. Bulatov

Centre for Process Integration, CEAS,

The University of Manchester, PO Box 88,

Manchester M60 1QD, UK

e-mail: igor.bulatov@manchester.ac.uk
}

and political challenges. The increasing urgency of these problems requires proactive approach on part of the scientific community, which needs closer collaboration between its members, the industry, policymakers and the general public. Various conferences which are being held around the world encourage closer collaboration among people of many nations in tackling the problems, and progress in meeting these challenges.

The series of conferences on "Process integration, modelling and optimisation for energy saving and pollution reduction" (PRES) is one such opportunity for cross-fertilisation. It was established originally to address issues relevant to process energy integration in connection with the thermal efficiency. However, it has now been expanded to focus on the wider field of energy, water, pollution and waste-related issues. The organisers of the PRES conferences are proud to continuously attract delegates from many countries world-wide, providing a friendly platform for the fast and efficient spreading of novel ideas, processes, procedures and policies.

This is now the first special issue of Clean Technologies and Environmental Policy. The PRES conference is also collaborating with several other known journals (Klemeš and Pierucci 2007; Klemeš and Stehlík 2007; Klemeš et al. 2007; Klemeš and Huisingh 2008). The collaboration with Clean Technologies and Environmental Policy is a fresh extension and has been mutually greatly appreciated.

The PRES conference is traditionally held every second year in the heart of Europe, and 2006 was no exception, the PRES2006 conference being held in Prague, the Czech Republic, between 27 and 31 August 2006. This Central European capital, known as a city of thousand spires, welcomed delegates from more than 50 countries. Besides traditional European countries, they represented Asia, Africa, Australia and North and South America. 
Overview of the papers included in this special issue: main thematic groups

For this special issue of Clean Technologies and Environmental Policy, ten documents representing various aspects of this field and related inputs are included. The internationality of PRES is reflected by the fact that competitively selected researchers from eight countries from Europe and Asia-Austria, Belgium, Czech Republic, Italy, Malaysia, Slovakia, Spain and the UK.

The first group of papers of this special issue deals with various aspects of the minimising the pollution and waste mainly by taking a proactive approach of recovery and transformation into valuable products.

The second group of papers covers similar aspects related to biomass and biogas. It also includes wastewater minimisation and reuse.

The last group of two papers is related to monitoring and prevention of pollution.

\section{Minimising the pollution by recovery and transformation}

This group presents a selection of five papers covering various recently developed directions. The first paper Catalytic and thermal cracking of selected polyolefins authored by Jozef Mikulec, Miriam Vrbova from Slovnaft VURUP, Bratislava, Slovakia, presents an important step for the development of feedstock recycling as a promising alternative for the management of plastic wastes. This may allow these residues to be transformed into valuable products for refinery and/or petrochemical industry. Catalytic degradation of polyolefin was carried out in a pilotscale reactor Blowdec ${ }^{\circledR}$ operating in the temperature range from 340 to $470^{\circ} \mathrm{C}$. The catalysts used in this study were natural zeolite clinoptilolite, ZSM-5, HZSM-5 and their mixture in various volume ratios. Both thermal and catalytic cracking of low-density polyethylene (LDPE), highdensity polyethylene (HDPE), polypropylene (PP) and their mixture have been investigated. Liquid products were checked in selected refinery and petrochemical processes as feedstock on the model pyrolysis pilot and with the help of microactivity tests.

The second contribution to this thematic group, Recovery and reutilisation of copper from metal hydroxide sludges, was presented by a joint team from School of Chemical and Environmental Engineering, University of Nottingham Malaysia Campus and Chemical Engineering Department, The University of Malaya-S. Vasanthi, A. R. Aziz, and M. K. Aroua. Sludges generated from electroplating wastewaters contain high concentrations of metals. The natural copper ore contains less than $1 \%$ of copper, whereas copper precipitate sludges from the electroplating industry may have an average of $5-10 \%$ of copper. In Malaysia, most of these metal-bearing sludges are disposed in specially engineering landfills. An experimental study was carried out to develop and optimise a method of copper recovery. Sludge samples containing high concentrations of copper were obtained from a local electroplating plant. This study introduces a sustainable method of utilising an electroplating sludge.

A Spanish team from Departamento de Ingeniería Química y Química Inorgánica, Universidad de Cantabri a-R. Aldaco, A. Garea; I. Fernández and A. Irabien, presented the paper, Resources reduction in the fluoride industry: fluoride removal and recovery in a fluidised bed crystalliser. Crystallisation process in a fluidised bed reactor appears as an alternative clean technology to the conventional chemical precipitation process. It contributes to an environmental friendly production reducing the waste production and improving the recovery of materials. The aim of this work was to scale up the crystallisation process in a FBR for the treatment of industrial fluoride wastewater. The technical viability of the process was concluded in agreement with the obtained results in laboratory scale, with fluoride recovery efficiencies in the reactor between 70 and $80 \%$ to form synthetic $\mathrm{CaF}_{2}$, which is able to be recycled as raw material for the production of hydrofluoric acid.

The forth contribution Persistent pollutants emission abatement in waste-to-energy systems came from Institute of Process and Environmental Engineering, Brno University of Technology UPEI VUT Brno, the Czech Republic. The authors Tomaš Pařízek, Ladislav Bebar and Petr Stehlík focused on analysing methods which enable a substantial reduction of persistent organic pollutants emissions to meet the environmental limits. Technologies based on adsorption of harmful compounds using activated carbon, technologies DeNOx/DeDiox and catalytic filtration using REMEDIA D/F material were considered and compared. An optimum design is based on computational support concerning the bag-house. It is illustrated through an industrial application of municipal solid waste incinerator with a capacity of $15 \mathrm{t} / \mathrm{h}(96,000 \mathrm{t} / \mathrm{y})$ of waste treated which is operated as a waste-to-energy system. These results and experience contribute to further improving the system.

The last contribution of this part Utilising high throughput technologies for the determination of the reaction network of the L-proline catalysed aldol reaction came from School of Chemical Engineering and Advanced Materials, University of Newcastle in the UK. The objective of the work of the authors-K. Novakovic, M. J. Willis and A. R. Wright - was to facilitate the determination of a reliable reaction network for the L-proline catalysed aldol 
reaction using high throughput technologies. The availability of reliable reaction network is fundamental to predictive kinetic modelling including scale up, replacing a batch process with a continuous one, optimisation, thermal safety, process simulation and finally minimising the pollution and waste. They staged experiments through a fourstage development programme. For this system is shown that meaningful data streams for mechanistic/kinetic studies can be generated. The experimental data allowed a novel reaction network for the L-proline-catalysed aldol reaction to be proposed and verified through a kinetic modelling exercise.

\section{Minimising the pollution and waste biomass and water-related processes}

The first work was presented by Francesca Accettola, Georg M. Guebitz and Rainer Schoeftner from PROFACTOR Produktionsforschungs $\mathrm{GmbH}$, Energie-and Umwelttechnologie Steyr/Gleink, and Graz University of Technology, Department of Environmental Biotechnology in Austria. Their paper Siloxane removal from biogas by biofiltration: biodegradation studies pays attention to volatile methyl siloxanes in biogas causing costly problems deriving from the formation of silicate-based deposits in biogas-fuelled power plant equipments. VMSs are being removed from biogas with high operational costs by adsorption on activated carbons. Biofiltration could be a cost effective and environmentally friendly alternative leading to a decrease in the cost of biogas treatment and enhancing its use for power generation. Presented results of biodegradation studies investigated the possibility of using biofiltration to treat biogas.

Measurements on the gas output revealed removal efficiency up to $20 \%$ when compared to a control under sterile conditions.

The second paper in this group was presented by Martin Miltner, Aleksander Makaruk, Michael Harasek and Anton Friedl from Vienna University of Technology, Institute of Chemical Engineering in Austria. It was titled Computational fluid dynamic (CFD) simulation of a solid biomass combustor: modelling approaches. They presented a work where CFD was used for the development and optimisation of an innovative combustion chamber for a solid stemshaped biofuel in the form of compressed biomass bales. The main focus was the maximisation of the thermal output of the combustor by optimising the bale burnout and the minimisation of gaseous emissions: VOCs, carbon monoxide and nitrogen oxide. The functionality of a commercial CFD-solver has been extended for the solid phase description and the solid-gas interactions. A simplified model for the prediction of $\mathrm{NO}_{x}$-emissions emanating from the fuel-bound nitrogen was implemented. Their work has shown that the application of CFD enables a significant reduction of the development costs and the time-to-market of innovative concepts of solid biomass combustion.

The third related paper in the group was Pragmatic software tools for water reuse evaluation in a factory presented by Etienne Brauns, Joost Helsen, Wim Schiettecatte and Inge Genné from VITO, Environmental and Process Technology, Mol in Belgium. They applied two steps to the process water optimisation supported by a software tool. The first step was the inventory of the different process streams in the process water network. The network was translated into a nodes diagram. The nodes were interconnected by selected process streams. A water balance of this steady-state water network model was set up. This prepared data for the second step. Software tools as WaterTracker ${ }^{\mathrm{TM}}$ (Linnhoff March KBC Energy Services) or WATER (Centre for Process Integration, The University of Manchester) are available and widely used. Specialised solver software is an alternative for some cases. The second step is the water usage optimisation through water pinch, which introduces the concept of water sources and water sinks within the set of process water streams (Wang and Smith 1994). Water pinch then looks for an optimal use of process water by combining sources and sinks in an intelligent way, taking into account the contaminant concentrations of the process streams, sinks and sources (Thevendiraraj et al. 2003). During this second phase software tools could be applied or at an elementary level could be used as a simplified combinatory approach programmed in e.g. Visual Basic. This provides evaluation of the complex combinatory sources-sinks problem, enabling a low cost and easy first interpretation of possible water-reuse opportunities. This should stimulate an enhanced analysis with advanced software tools.

\section{Monitoring and prevention of pollution}

There are two papers in this group. The first one-On the aerosols monitoring by satellite observations was presented by Emiliano Ortore, Valerio Francione from Aerospace Engineering School, University of Rome 'La Sapienza' in Italy. The presence of particulate matter-a complex mixture of organic and inorganic particles (aerosols) that can be found suspended in the atmosphere in solid, liquid or both physical states of non-natural originis linked to important climatic and environmental effects. The aerosols can contaminate a wide area of the region surrounding the source of particulate. For these reasons, it is the utmost importance to develop a satellite-based system capable of monitoring the presence of particulate on 
very large areas. This paper provided methodologies to identify atmospheric particles by means of satellite-based sensors operating both in the reflective and in the thermal infrared part of the electromagnetic spectrum.

The second contribution is from Spain-Integrated pollution prevention and control in the surface treatment industries in Galicia (NW Spain) presented by M. C. Barros, M. T. Torres, P. M. Bello, E. Roca and J.J. Casares from Department of Chemical Engineering. University of Santiago de Compostela, Spain. The IPPC Directive concerning integrated pollution prevention and control came into force 10 years ago affecting to the industrial processes being highly polluting sources. The Directive demands that an integrated environmental permit should be granted by the competent authority of the region they are located. This permit should include the emission limit values taking into account the best available techniques (BAT). This paper presents an application of this law to the surface treatment sector using electrolytic or chemical procedures in Galicia (NW Spain). An overview of the sector was analysing the productive operations applied and their environmental aspects to prevent and/or reduce the potential pollution. A simple method for determining whether a technique consideration is a BAT is included. A support guide to apply for the environmental permit was developed.

\section{Conclusions}

This year the special issue has revealed that Cleaner Production is continuing to produce strong interest and is still developing in new directions and fields. We will all watch with great interest future research results which will be presented at future PRES conferences.

We trust that the papers in this special issue of Clean Technologies and Environmental Policy will be of interest and relevance to a broad range of the scientific community and will bring to their attention the PRES Conference series as well.

The help of all collaborators and the ISC members (PRES Conference Website 2007) is gratefully acknowledged both for actively contributing to the conference and for taking part in the reviewing process. A special appreciation is being expressed to all authors for their contribution.

We would like to continue and further develop the mutual collaboration between Clean Technologies and Environmental Policy and PRES conference series. The ninth conference PRES' 07 was very successfully organised jointly with ICheaP-07 in the Island of Ischia, Gulf of Naples, Italy, and another special issue has been already prepared. The following tenth PRES 2008 will again return to "golden Prague" between 24 and 28 August 2008 and again jointly with CHISA 2008.

\section{References}

Klemeš J, Huisingh D (2008) Economic use of renewable resources, LCA, cleaner batch processes and minimising emissions and wastewater. J Clean Prod 16:159-163

Klemeš J, Pierucci S (2007) Advanced combustion, cooling and refrigeration, waste gas treatment, heat integrated separation and case studies. Appl Therm Eng 27(7):1133-1137

Klemeš J, Stehlík P (2007) Heat integration, energy management, $\mathrm{CO} 2$ capture and heat transfer enhancement. Appl Therm Eng 27:2627-263

Klemeš J, Pierucci S, Worrell E (2007) Sustainable processes thorough LCA, process integration and optimal design. Resour Conserv Recycl 50(2):115-121

PRES Conference. http://www.conferencepres.com. Accessed 30 August 2007

Thevendiraraj S, Klemeš J, Paz D, Aso G, Cardenas GJ (2003) Water and wastewater minimisation on a citrus plant, resources. Conserv Recycl 37(3):227-250

Wang Y-P, Smith R (1994) Waste water minimisation. Chem Eng Sci 49(7):981-1006 